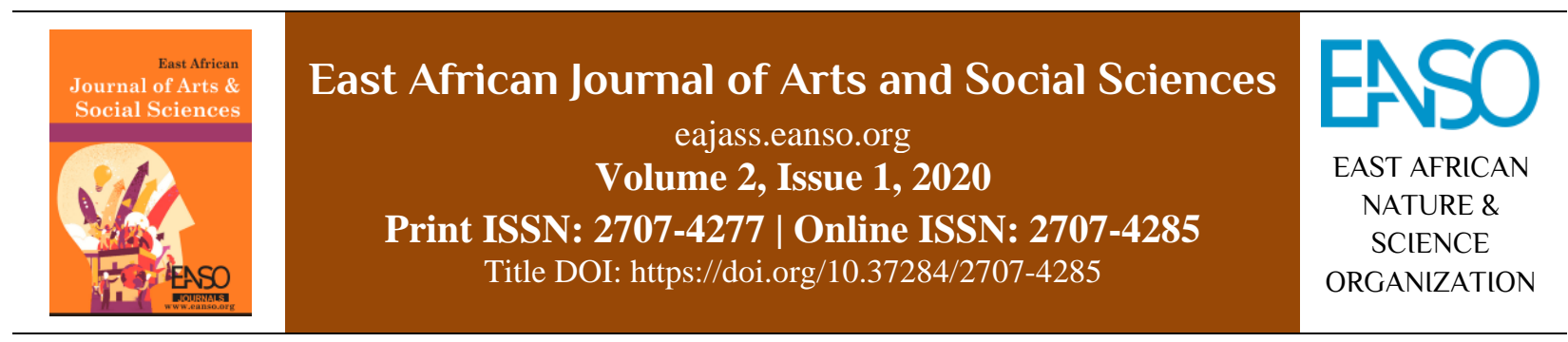

Original Article

\title{
Evaluation of Incorporation of Universal Design Parameters in the Planning Approval Process of Kisumu Main Bus Terminus
}

\author{
Ahonobadha Marilyn Ochieng ${ }^{\prime *}$, George Mark Onyango,PhD ${ }^{l} \&$ George Godwin Wagah, PhD ${ }^{1}$ \\ ${ }^{1}$ School of Arts and Social Sciences, Maseno University, P. O. Box 333, Maseno, Kenya. \\ *ORCID: https://orcid.org/0000-0003-2395-7609; Author for Correspondence email: ahonobadha79@ gmail.com.
}

Article DOI: https://doi.org/10.37284/eajass.3.1.261

\section{Article history: ABSTRACT}

05 January 2021 Consideration of the normate template by designers usually leads to the production of living spaces that fail to meet most of the spatial requirements of

Keywords: would-be users. This phenomenon arises due to the fact that the normate template keeps a walking and fleshy body at the centre of thinking about design.

Universal Design, As a result, the template fails to consider additional space requirements for Planning Practice, bodies that use technologies to navigate space. In order to sustain itself, the Кisuти City. normate template relies upon the impression that normates are normal, average, and majority bodies. When built-up spaces block out potential users, then the viewpoint which is reinforced is that certain spaces are meant only for those who are "privileged" to use these spaces independently. The presence of accessible spaces on the other hand confirms that designers hold that built environments should serve all potential users regardless of physical stature. Universal Design thereby provides a platform for making the weakest person in society strong through design. Embracement of a Universal Design perspective therefore becomes a stepping stone in the provision of public spaces that are accessible to all- regardless of physical stature. This study, therefore, evaluated the incorporation of Universal Design parameters in the design process of public spaces in Kisumu City. The study established that Universal Design requirements are usually executed only on new constructions. There is a need, therefore for major renovations to take place in buildings open to the public that are not necessarily classified as "new" constructions.

\section{APA CITATION}

Ochieng', A. M., Onyango, G. M., \& Wagah, G. G. (2021). Evaluation of Incorporation of Universal Design Parameters in the Planning Approval Process of Kisumu Main Bus Terminus. East African Journal of Arts and Social Sciences, 3(1), $12-23$. https://doi.org/10.37284/eajass.3.1.261 


\section{CHICAGO CITATION}

Ochieng', Ahonobadha Marilyn, George Mark Onyango, and George Godwin Wagah. 2021. "Evaluation of Incorporation of Universal Design Parameters in the Planning Approval Process of Kisumu Main Bus Terminus". East African Journal of Arts and Social Sciences 3 (1), 12-23. https://doi.org/10.37284/eajass.3.1.261.

\section{HARVARD CITATION}

Ochieng', A. M., Onyango, G. M. and Wagah, G. G. (2021) "Evaluation of Incorporation of Universal Design Parameters in the Planning Approval Process of Kisumu Main Bus Terminus”, East African Journal of Arts and Social Sciences, 2(1), pp. 12-23. doi: 10.37284/eajass.3.1.223.

\section{IEEE CITATION}

A. M. Ochieng', G. M. Onyango, and G. G. Wagah, "Evaluation of Incorporation of Universal Design Parameters in the Planning Approval Process of Kisumu Main Bus Terminus”, EAJASS, vol. 3, no. 1, pp. 12-23, Jan. 2021.

\section{MLA CITATION}

Ochieng', Ahonobadha Marilyn, George Mark Onyango, and George Godwin Wagah. "Evaluation of Incorporation of Universal Design Parameters in the Planning Approval Process of Kisumu Main Bus Terminus". East African Journal of Arts and Social Sciences, Vol. 3, no. 1, Jan. 2021, pp. 12-23, doi:10.37284/eajass.3.1.261.

\section{INTRODUCTION}

The Constitution of Kenya (GoK, 2010) advocates for non-discrimination against any segment of society on any ground. Further, the Government of Kenya has enacted various legislations upholding the right of entry by all to spaces open to the public. Examples of such legislation include the Persons with Disabilities Act (2003), Urban Areas and Cities Act (2011), and the National Construction Authority Act (2011). These legislations all feed into Universal Design (UD) stipulations which require that environments should be accessible to all regardless of age, size or physical status.

The task of UD is to make the way buildings are designed explicitly so as to hold designers accountable for what appears to be disabilityneutral design, and show that this neutrality is a constructed form of ignorance. Making UD's values and ideologies explicit requires consideration of excluded bodies and full acknowledgement of the range of interactions between bodies and environments. Because the normate template keeps a walking and fleshy body at the centre of thinking about design, buildings often fail to consider space requirements for bodies that use technologies to navigate space (Hamraie, 2013). This observation squarely placed the issue of accessibility or lack thereof on planners and designers. Adherence to the normate template would give rise to a situation where environments are "inclusive" to those who can "fit". Such a scenario passes non-verbal cues to members of society who are locked out of the given public spaces. The converse was true since adherence to UD would ensure that the built-up environment was accessible to all, regardless of physical ability. The purpose of this study therefore was to evaluate the incorporation of Universal Design Parameters in the design approval process of Kisumu main bus terminus.

\section{LITERATURE REVIEW}

Bus terminus designs present a visible and tangible proof of the view of planning institutions and designers towards those who could not operate within the $5^{\text {th }}$ and $95^{\text {th }}$ percentiles. Execution of designs that privilege some while locking out others would show that designers and planners consider those who were locked out spatially as "misfits". During instances when the executed design privileges some while locking out others, then the non-verbal cue which would be passed across is that planners and designers are biased against "spatial misfits". The message passed out to the segment of the populace which cannot operate in the spaces set forth would be that they are not considered as potential users of public spaces. 
Designers have a direct impact on bus terminus design since they are the ones who conceptualise the spaces, right from the sketching phase to the project execution phase. During this design process, the designer has to decide whether to take a UD approach or a normate template approach. Planners on the other hand are the ones who give planning approval to designs of the built environment. During the approval of plans, Planners also have a choice of taking a UD approach or a normate template approach. The same scenario would play out during planning approval since the planners have tools to sieve out developments biased towards the normate template

Accessibility has been a well-known concept in the transport planning field since the 1950s when it was introduced as ease of reaching desirable destinations tying land use and activity systems with the transport networks that serve them. Improving accessibility has recently emerged as a central aim of Urban Planners and aligned disciplines (Iacono, Krizek and El-Geneidy, 2010). Transport planning literature contains many measures largely restricted to motorised modes and a handful of destination activities. There is a need to explore issues related to the development of accessibility measures for non-motorised modes, namely bicycling and walking (Iacono, Krizek, and El-Geneidy, 2010). One facet of improving accessibility utilised by this study was the evaluation of the specific components of a transport terminus to commuters during instances they became pedestrians. The viewpoint held by the researcher was that improved access to infrastructure would support potential users to approach, enter and make use of the facilities independently and safely.

Prevailing attitudes towards disability and how it is understood in a society can be represented in the construction process and the product of its built environments. Inaccessible built environments act to reinforce the social marginalisation faced by disabled people (Sawadsri, 2011). Inaccessible bus terminus facilities, therefore, became active agents of social exclusion due to their segregating nature. Bus termini designed after a normate template would pass out non-verbal cues of exclusion of PwDs (Persons with Disabilities), while one designed with a UD outlook would enhance inclusivity of all, including PwDs.

Within the societal setup, investments are usually made in areas which are considered valuable, while areas not considered valuable are not located substantial resources. Although designers do not create these social categories, they play a key role in providing the physical framework in which the socially acceptable is celebrated and the unacceptable is confined and contained. Thus, when any group that has been physically segregated or excluded protests its second-class status, its members are in effect challenging how designers practice their profession (Hamraie, 2013).

The design process usually begins with a design specification where the requirements of a design are specified. At this stage, the needs are formulated as complete as possible indicating the intent of the design as precisely as possible. Unfortunately, in practice, the specification does not contain a complete definition or all relevant facts a designer would need to come up with a proper solution. As a result, one gets a conceptual formulation of needs which has to be developed and evolved like the whole design has to be. The goal of the design specification is to analyse, describe and expose the aim of a design so that the purpose and the intention of a given design are formulated. The result is a design specification which contains requirement a product or artefact has to meet (Lossack and Grabowski, 2000).

In the design of accessible bus termini, elements enhancing access can be captured when design specifications are being drawn out. Conversely, lack of compliance to UD requirements leads to the construction of facilities which hamper independence and mobility of people who do not 
conform to the normate template. Adherence to UD requirements leads to the formation of environments which benefit a wide range of people, including those with heavy luggage, expectant mothers, people with disabilities and little children. This study therefore evaluated the existing mindset as far as design specifications of termini in the Western part of Kenya were concerned.

Value-explicit design does not privilege expert knowledge, but rather provides a framework within which designers can be held accountable for the types of environments that they produce. (Hamraie, 2013). Accessible bus termini communicate the viewpoint that all members of society are welcome to use the facilities. UD parameters, therefore, provide a starting point for designers and planners to evaluate the extent to which designs they have control over encourage access or inhibit the same.

Since the normate template keeps a walking and fleshy body at the centre of thinking about design, buildings often fail to consider space requirements for bodies that use technologies to navigate space. In order to sustain itself, the normate template relies upon the impression that normates are normal, average, and majority bodies (Hamraie, 2013). While designing products and environments, designers often focus on the average user (Burgstahler, 2009). Inaccessible spaces thereby locked out a segment of the population that could not fit into the "ideal" environments presented by designers and planners. UD therefore presented a framework within which planners could be held accountable for the building forms they approved. Accessible spaces, on the other hand, would benefit not only the wheelchair user but also the traveller having a lot of luggage, the parent pushing a pram or the obese commuter.

Building forms reflect how society feels about itself and the world it inhabits (Hamraie, 2013). Universal design has the power to lift the human spirit, especially when environments are designed to truly meet the needs of people who use them.
Universal design encompasses the inclusive and non-discriminatory design of architecture, urban environments and infrastructure. The principles advanced by UD can be related directly to control mechanisms common in planning, such as building codes, zoning regulations, design review, tax incentives and guidance UD principles are lofty ideals and guiding principles that need to become more quantified and operational so that planners and designers can use them in their projects. (Preiser, 2007).

A study by Kimani and Musungu (2010) on planning and building regulations in Kenya established that development control is hampered by lack of capacity to inspect and implement plans, lack of relevant supportive systems for effective enforcement and lack of resources. A report on the state of the built environment in Kenya notes that the Kenya Building code and regulations are still concerned with traditional liability and life safety issues. In addition to this, the Building Code has not been revised to date (NBR, 2014). Further, the content of the building code in Kenya was formulated from the British Imperial Codes existing in 1969 (Erastus and Wuchuan, 2014).

Observations from these studies put forth a complex scenario. On the one hand, there exists an inefficient system, while on the other hand, the regulations governing the building sector are outdated. In light of these challenges, UD provides a platform for ensuring that the design process of termini gives rise to accessible facilities, despite the handicap presented by the building code.

It is important to note that the design process of solving problems is embodied within UD since it is both intentional and intuitive (Depoy and Gilson, 2010). Design knowledge is based on intuitive investigation and problem-solving by individual designers. Within design practice, "research" refers to the designer's drawings, studies, and models that explore possibilities for a design. Whereas scientific research describes an existing state of 
things, the design is a process that researches potential futures by solving problems within the status quo (Lawson, 1997). Three intersecting approaches that contribute to the advancement of UD are: strengthening regulations in order to increase the acceptable baseline; spreading knowledge through speaking, teaching and writing; and building support through advocacy and representation (Ruptash, 2013).

\section{RESEARCH METHODS}

Key informant interviews were used to gather information incorporation of Universal Design parameters in the design process of the main bus terminus in Kisumu City. The researcher evaluated the design process of termini in the study area from the project conceptualisation stage to actualisation. Four designers of termini were interviewed so as to establish whether UD principles were considered during the planning and execution of designs.

An additional four key informants were drawn from the Planning offices in the study area. Planners were interviewed so as to establish whether UD principles were considered as a requirement before planning approval of public facilities like termini was granted. Lastly, an additional four key informants were drawn from personnel in charge of the management of the termini. The total number of KII used for this study was twelve.

\section{RESULTS AND DISCUSSION}

\section{Functions of Planning Offices in the Study Area}

\section{State of Termini in Study Area}

Upon inquiry into the state of the main bus terminus, one informant based in Kisumu County Planning Office pointed out that when the Kisumu terminus was put up, they played a supervisory role, rather than a vetting one. One informant explained the situation this way:

When Kisumu terminus was put up, the personnel in the Advisory Committee were not able to point out mistakes existing in the given designs since they only oversaw the construction process (Architect).

Within the study area, some barriers existed due to wear and tear as is highlighted below:

Some barriers have arisen due to wear and tear. As a result, you will find out that barriers in circulation paths arise due to eroded drop-offs and pavements (Architect).

\section{Legislations used in Development Control}

Key informants in the study area noted that the design of bus termini was governed by provisions in the Physical Planning Act. One informant mentioned the following:

The Physical Planning Department usually refers to the following legislations when approving developments: the Physical Planning Act, the Public Health Act and the Building Code. The responsible authority for approval of Plans is the County Government (Planner).

These provisions in the various legislations highlighted guided the preparation and implementation of physical development plans. The researcher noted that the list provided by the informant was not exhaustive since other legislation governing the built environment include the National Construction Authority Act, the Urban Areas and Cities Act, the Persons with Disabilities Act, the Constitution of Kenya and the United Nations Commission on the Rights of Persons with Disabilities.

Upon inquiry whether accessibility advisory committees existed in the study area, an informant stated the following:

Accessibility Advisory Committees exist in the study area. Its members usually go for periodic trainings organised by the Architectural Association of Kenya (AAK) or the Kenya Institute of Planners. These committees review 
site plans and drawings in a timely manner. Due to the existence of these committees, accessibility features such as curb cuts, ramps, grate design and location, and grade elevations are required to be implemented in new constructions (Architect).

The focus of UD requirements in the study area seems to be on new constructions and not on renovations of existing structures. This may be one reason why termini in the study area have design barriers. Upon further inquiry whether economic incentives were given by the Kisumu County government so as to ensure that barriers were eliminated from termini, the following was revealed:

Economic incentives are not given by the County governments to ensure that UD features are incorporated into the built environment. Project developers are, however, free to apply to bodies advocating for UD (Planner).

A paradox situation hereby arises with this revelation that there are specific bodies to be applied to for funds. On the one hand, the bus termini are under the control and management of the County government. In addition to this, the County government usually collects funds from the main bus terminus. The ideal situation would be that the County government would be at the forefront in organising for the renovation of the main bus terminus, rather than applying for funds to bodies advocating for UD.

When commenting on the design process of termini, an informant highlighted the following:

The building By-Law which is in use is only concerned with issues on materials used for construction and fire safety of potential users of a space. This By-Law does not take into consideration issues of equitable access as has been spelt out in UD requirements. A Reviewed Building Code which clearly articulates UD issues exists. This Code has however not been adopted for use (Architect).

There is a need therefore for the Government of Kenya to adopt and use the revised Building Code so as to ensure that issues of UD trickle down to the design of bus termini and other building facilities open to the public. While commenting on the building code, one informant stated that:

The building code has a bias to space provision within a housing unit and not a public space (Architect).

Another informant further suggested the following:

Since the current building code is still in use, $U D$ requirements should be included in the circulars and physical development plans so that equitable access by potential users is incorporated into project plans before project inception, while the terms of reference are being drawn out. Decision-makers in a project have a key role to play as far as implementation of UD is concerned, they should be made aware of spatial-technical standards that enhance access for all (Architect).

This observation highlights a pertinent UD issue which is the level of awareness of UD among project developers. In the case of the bus termini, awareness of the Ministers at the County level in charge of termini translates to accessible termini. Other actors involved in project execution include the Members of County Assemblies who would be instrumental in passing the necessary legislation for the renovation of termini. The County Governors should also be made aware of UD specifications and requirements. In this way, public spaces will not be agents of spatial exclusion since equitable access will be ensured right from the time the terms of reference for projects are being drawn out. 
One informant noted the following:

There is a need for harmonisation between legislation governing the design of the built-up environment and those advocating for equitable access. Such an exercise will ensure that clauses encompassing equitable access which have been spelt out in the legislation can be implemented while projects are still at the conceptualisation stage (Planner).

\section{Universal Design Requirements}

The researcher queried whether there were provisions for the use of International and Universal symbols. One informant had the following to say:

The issue of the use of international and universal symbols and tactile signage in termini is still in progress (Architect).

The researcher noted that none of the areas in the bus terminus in the study area had incorporated international and universal symbols. A possible reason could be that the accessible spaces in the terminus lack in the first place. As a result, it would be improper to post signage demarcating an area as accessible, while the area is full of barriers. A possible point of intervention would be the removal of identified barriers, upon which appropriate signage can be posted in the termini.

When asked to comment on the state of UD in termini in the study area, the following comments were made:

We have come a long way (Planner).

We have a well-developed policy, including most of the necessary laws, provisions, regulations etc., but there is still work to do in this field (Architect).

Another informant stated:

We are improving, but slowly (Planner).
Another informant noted:

The legal framework used in the design process of termini is directed mainly towards universal design/design for all rather than mainly towards disabled people as a specific group (Planner).

Although these observations were commendable, the fact on the ground confirms that bus terminus designs are filled with design barriers that hinder mobility, independence and spatial inclusion of users who cannot fit into a normate template.

\section{Ongoing Barrier Removal in the Terminus}

When asked to comment on the influence of various groups and factors on the development of a legal framework advocating for equitable access in the last five years, the following comments were made:

So far, politicians have had a low impact on the development of a legal framework advocating for equitable access (Planner).

Another informant had this to say:

User groups have had a low impact factor although experts have had a moderate influence. Development in other countries has also had a low impact on the execution of projects so far (Planner).

Further analysis of these comments reveals that since user groups have had a low impact factor in articulating issues that affect the legislations governing development control have not factored in the spatial needs of those who use assistive devices. Another point highlighted by these comments is that since development in other countries has had a low impact on legislations used locally, Kisumu County Planning Office has not engaged in a benchmarking exercise in the past five years. As a consequence, personnel in the planning office have not learnt from Best Practice in other countries that have succeeded in implementing UD. 
When asked to clarify the presence of indicator systems on the accessibility of public transport systems, the following comment was made:

No indicator system has been developed to measure developments in the accessibility of public transport systems, either for specific parts of the travel chain or for the whole travel chain (Architect).

The absence of such an indicator system means barriers arising due to wear and tear have not been dealt with. Further, on-going barrier removal is currently not viewed as an obligation by the County Government. Based on the comments presented in the sections above, it becomes clear that as much as the County government has stated that it is committed to UD in bus termini, the facts on the ground dispute this claim.

Petrén (2014) confirms that the design of built environments can exclude or include depending on the quality of execution and the decisions behind the same. Based on the findings of the study, it becomes clear that a disconnect seems to exist in terms of erection and maintenance of termini and the UD knowledge of personnel of the Planning Office.

The researcher confirmed that Personnel in the Planning Office seemed to be very knowledgeable on UD issues. Despite this knowledge, Kisumu's main terminus was full of barriers that hampered mobility, safety and independence of potential users. By extension, a greater percentage of the populace experienced these barriers whenever they made use of termini. This percentage would include travellers having luggage on castors, expectant mothers, obese travellers and others who were disabled permanently or temporarily.

Lewis, McQuade and Thomas (2005) put forth a strong argument that most environments are designed for the average individual. The average individual is a myth which only exists in anthropometric tables and ergonomics classrooms.
One of the most important tasks in today's society is to create and build habitable worlds for all people and build habitable worlds for all people throughout their life span (Petrén, 2014). This implies that the starting point should not be a fiction of a normal, average person, but diverse in all aspects (Lid, 2013).

The presence of design barriers in the study area highlights the fact that the Kisumu terminus was designed with the average individual in mind. As a consequence, spaces and facilities in this terminus fail to meet the requirements of most users. Such a scenario leads to the spatial exclusion of individuals who are not "privileged" to fit in spaces presented therein.

Since the planners and designers are knowledgeable on UD requirements, the most obvious point of intervention is to plan for renovations of the terminus. These renovations should be outlined in such a way that designs move away from the fictitious user of public areas. The renovations will help ensure that the terminus is accessible to all regardless of physical status. Indeed, flexible spaces will cater to individuals irrespective of their age or physical ability.

Design for all (DfA) is a general approach to decision making, planning and design which represents a new paradigm moving from the "average person" to human diversity as a starting point for decision making and design process. DfA is a design response to major societal challenges, one of the biggest being enabling the largest possible number of people to live independently and take part in everything that constitutes society. The DFA approach and methodology goes beyond regulations and standards to translate societal challenges into creative opportunities (Petrén, 2014).

In this way, the onus of all-inclusiveness becomes a prerogative for both planners and designers. Planners would put in place the required legal 
framework while designers would incorporate strategies that make the weakest person in society strong through design. On the maintenance of termini, informants confirmed that indicator systems to measure developments in the accessibility of public transport systems had not been developed. As a result, barriers resulting from wear and tear take a long time to be addressed.

Jonsson (2014) notes that design can be regarded as a finite process ending up in infrastructure or a product, or it can be regarded as an infinite process that includes actions and using in the very moment. Further, the design is never neutral; it has effects on human existence and behaviour. In the context of the study area, there is a need for recognition of the fact that although the bus terminus has been put up, designers should not assume that their task is done. Instead, periodical evaluations of the components of the terminus should be done in light of UD requirements. Once this is done, barriers arising from wear and tear can be identified and eliminated.

The existing challenge in the study area therefore is for planners and designers to acknowledge that designs have an effect on users of public space, long after a project has been completed and commissioned. Within the study area, the presence of design barriers affects accessibility negatively. The presence of barriers hampers the independence, mobility and spatial inclusion of some segments of society. The goal therefore is to ensure that designs implemented in public spaces like termini enhance the inclusion of all potential users- regardless of their physical stature.

Enabling environments are the ones that encourage the participation and inclusion of individuals with disabilities in social life. Such environments require accessibility to be ingrained in the building industry, and that accessibility standards and UD are the main tools for creating enabling environments (Issa Abdou, 2014). Planners and designers should therefore strive to ensure that bus terminus designs uphold the minimum requirements for equitable access as far as UD is concerned. Planners and designers therefore have an obligation to ensure that enabling environments are put up. Retrofitting termini can also be pursued as an avenue to ensure access for all. Incorporation of UD parameters in bus terminus designs will help eliminate disabling barriers which have a negative effect on people's ability to navigate through spaces independently and safely.

In the recent past, there has been an emergence of a universal philosophy for environmental and product comfort. Safety and usability have been embraced worldwide as the ultimate design agenda. Universality has become the standard by which design excellence is measured and recognised. By examining successful approaches and interventions, practitioners are presented with a blueprint and guidelines for future accomplishments and a world of equity by design (Moore, 2014). The onus is hereby placed on Planners and designers in the study area to examine examples of "Best Practice" and establish areas where they can learn from success stories of other countries. Such a step may be the basis for the provision of accessible termini adhering to UD standards.

Kar and Mullick (2014) propose that interdisciplinary planning, follow-up, implementation and assessment of a given design is important. Important aspects of a UD process include: holistic and interdisciplinary, based on user-centred design, adoption and application of accessibility guidelines and standards, iterative development, focus on users with diverse accessibility needs and their usage contexts early and throughout the development process, empirical evaluations and focus on whole user experience.

The design of public spaces usually passes out nonverbal cues to the populace. On the one hand, people who cannot fit into a given space receive non-verbal cues which affirm the fact that they are not considered as potential users of a given space. 
Based on this communication, inaccessible termini make the argument that disabled bodies are unworthy of inclusion since this category of persons is not considered as potential spatial inhabitants.

Hamraie (2013) explains further that although designers do not create social categories, they play a key role in providing the physical framework in which the socially acceptable is celebrated and the unacceptable is confined and contained. Thus, when any group that has been physically segregated or excluded protests its second-class status, its members are in effect challenging how designers practice their profession (Hamraie, 2013). A possible point of intervention within the study area towards compliance of UD in the study area would be the renovation of the bus terminus so that the Planners and Designers can apply the UD knowledge which they have in their custody.

These three approaches will help embed UD in the built environment. In this way, designers of public facilities can take into account the full diversity of the potential user population. In addition to this, people who are usually considered as having a disability are only a small part of the population of people with reduced functionality. The vast majority of people have some functionality that is significantly less than the norm, and most people go through phases in which they are temporarily disabled by accident, alcohol, drugs, stress, or even fatigue (Newell and Gregor, 2002).

Despite the advancement of minimum standards for $\mathrm{UD}$, it is important to remember that on the basis of this paradigm, UD should be interpreted as respect for human dignity. If separated from the human condition, there is a risk that UD may be reduced to a minimum standard and thus fail to develop its full democratic potential (Lid, 2013). In conclusion, the social model of disability puts forth a strong argument that discrimination against persons with disability can stop only when barriers put in place by society are torn down (Paar and Butler, 1999).
Designers and planners of bus termini therefore have a key role to play in making this observation a reality. The design of the termini should not therefore encourage barrier formation which privileges certain people while excluding others.

\section{CONCLUSIONS AND RECOMMENDATIONS}

Despite awareness of UD requirements, the main bus terminus in Kisumu has various physical barriers that have arisen due to inappropriate construction practices on the one hand and wear and tear on the other hand. Currently, the area of focus as far as UD issues are concerned is new constructions. As a consequence, the main bus terminus- though frequented by a significant portion of the populace has not come under consideration as a potential project as far as UD is concerned.

There is a need for harmonisation between legislations governing the design of the built-up environment and those advocating for equitable access. Further, a monitoring and evaluation unit should be set up so that barriers arising due to wear and tear in amenities are identified and eliminated. Existing legislations that articulate UD issues should be made reference to during these renovations.

\section{ACKNOWLEDGEMENT}

The researchers would like to acknowledge the funding from Kisumu Local Interaction Platform (KLIP) and Mistra Urban Futures. The funding was used to carry out the research and also pay the publication fee. 


\section{REFERENCES}

Burgstahler, S. (2009). A goal and a process that can be applied to the design of any product or environment. University of Washington.

Depoy, E., \& Gilson, S. (2013). Disability, design, and branding: Rethinking disability within the 21st century. The Disability Studies Reader, 3 (2).

Erastus, K. K., \& Wuchuan, P. (2014). Flaws in the Current Building Code and Code Making Process in Kenya. Civil and Environmental Research, 6(5), 24-30.

Government of Kenya (GOK). (2004). The Persons with Disabilities Act. Kenya Gazette Supplement. Nairobi: Government Printer.

Government of Kenya (GoK). (2010). The Constitution of Kenya. Kenya Gazette Supplement. Nairobi: Government Printer.

Government of Kenya. (2011). The National Construction Authority Act. Kenya Gazette Supplement. Nairobi: Government Printer.

Government of Kenya. (2011). The Urban Areas and Cities Act. Kenya Gazette Supplement. Nairobi: Government Printer.

Hamraie, A. (2013). Designing Collective Access: A Feminist Disability Theory of Universal Design. Centre for Medicine Health and Society. Vanderbilt University.

Iacono, M., Krizek, K. J., \& El-Geneidy, A. (2010). Measuring non-motorised accessibility: issues, alternatives, and execution. Journal of Transport Geography, 18(1), 133-140.

Issa Abdou, S. M. (2014). An Analytical Approach to People with Disabilities Mainstreaming Policies In Western and Arab Countries. In Universal Design 2014: Three Days of Creativity and Diversity: Proceedings of the
International Conference on Universal Design, UD 2014 Lund, Sweden, June 16-18, 2014 (Vol. 35, p. 26). IOS Press.

Jonsson, B. (2014). Variation, multifoldness and dynamics as the mothers of learning, universality and design. Universal Design 2014: Three days of creativity and diversity (pp. 3546). Amsterdam: IOS Press BV.

Kar, G. \& Mullick, A. (2014). Designing universal workspaces. Proceedings from Universal Design 2014: Three days of creativity and diversity (p. 69-79.). IOS Press.

Kimani, M. \& Musungu, T. (2010). Reforming and restructuring planning and building laws and regulations in Kenya for sustainable urban development. In 46th ISOCARP Congress (p. p8).

Lawson, B. (1997). How Designers Think: The Design Process Demystified. Architectural Press

Lewis, C., McQuade, J., \& Thomas, C. (2005, September). Measuring physical access barriers to services: 'Snapshot'research in 4 town/city centres in Britain. In International Congress Series (Vol. 1282, pp. 1034-1037). Elsevier.

Lid, M. (2013). An ethical perspective. In Trends in universal design. In Trends in Universal Design: An Anthology with Global Perspectives, Theoretical Aspects and Real-World Examples (p. 46-51). Tønsberg, Norway: Norwegian Directorate for Children, Youth and Family Affairs, The Delta Centre.

Lossack, R., \& Grabowski, H. (2000). The axiomatic approach in the universal design theory. In ICAD2000, 1st International Conference on Axiomatic Design (pp. 21-23). Cambridge.

Moore, P. (2014). A history of UD: Today's exemplars and tomorrows opportunities. 
Proceedings for Universal Design 2014: Three days of creativity and diversity. IOS Press.

National Building Regulations (NBR). (2014). Regulations for a safer, attractive and wellplanned built environment. Nairobi: National Building Regulations.

Newell, A. F., \& Gregor, P. (2002). Design for older and disabled people-where do we go from here?. Universal Access in the Information Society, 2(1), 3-7.

Paar, H. \& Butler, R. (1999). New geographies of illness, impairment and disability in mind and body spaces. New York: Routledge.

Petrén, F. (2014). Turning societal challenges into creative opportunities. Assistive Technology Research Series, 35, 11-12.

Preiser, W. (2007). The Seven Principles of Universal Design into planning practice. In J. Nasar and J. Evans-Cowley (Eds.), Universal design and visitability: from accessibility to zoning (p. 11-30). Columbus, Ohio: The John Glenn School of Public Affairs

Ruptash, S. (2013). How to promote UD through passion, knowledge and regulations. Trends in universal design. In Trends in Universal Design: An Anthology with Global Perspectives, Theoretical Aspects and Real-World Examples (p. 24-27). Tønsberg, Norway: Norwegian Directorate for Children, Youth and Family Affairs, The Delta Centre.

Sawadsri, A. (2011). Embodiment in the disabling built-environment: an experience of daily life. Forum Ejournal, 10, 53-66. 